\title{
Superconducting $\mathrm{Y}-\mathrm{Ba}-\mathrm{Cu}-\mathrm{O}$ films by rf sputtering in axial magnetic field
}

\author{
R PINTO, S P PAI and L C GUPTA* \\ Solid State Electronics Group, *Solid State Physics Group, Tata Institute of Fundamental \\ Research, Homi Bhabha Road, Bombay 400005, India

\begin{abstract}
Films of $\mathrm{Y}-\mathrm{Ba}-\mathrm{Cu}-\mathrm{O}$ system have been prepared by $\mathrm{ff}$ sputtering from composite $\mathrm{Y}-\mathrm{Ba}-\mathrm{Cu}-\mathrm{O}$ targets in an axial magnetic field in 4:1 $\mathrm{Ar} / \mathrm{O}_{2}$ mixture on $\langle 100\rangle \mathrm{SrTiO}_{3}$ and $\langle 100\rangle \mathrm{MgO}$ substrates at $270^{\circ} \mathrm{C}$ and $450^{\circ} \mathrm{C}$. Although back-sputtering caused due to negatively-charged oxygen ions was found to drastically vary the film composition about the centre of the sputtering axis, by properly orienting the substrates with respect to the sputtering axis near-stoichiometric films have been obtained. Films annealed at $900^{\circ} \mathrm{C}$ in oxygen have shown superconducting onset at $88^{\circ} \mathrm{K}$ and zero resistance transition at $72^{\circ} \mathrm{K}$.
\end{abstract}

Keywords. Superconducting films; YBaCuO system; rf sputtering; backsputtering; growth; resistivity.

\section{Introduction}

Among the various techniques used during the last two years for the growth of high transition temperature superconducting films (Adachi et al 1987a; Chaudhari et al 1987; Kwo et al 1987; Wu et al 1987), sputtering technique has shown significant promise (Adachi et al 1987a; Aida et al 1987; Hong et al 1988). This is because, although the sputtering process is itself complex, the rate of sputtering can be easily controlled and a composite target can be used (Hong et al 1988; Kentgens et al 1988) eliminating the multiple sources which are required in the case of evaporation process (K wo et al 1987). Equally important is the fact that high oxygen partial pressures required for the growth of oxide superconductors can be provided during sputtering since, unlike in the case of evaporation, sputtering electrodes are compatible with high oxygen partial pressures.

However, one of the main problems with sputtering is the generation of negative ions especially with oxygen partial pressures (Kentgens et al 1988; Broussard and Wolf 1988). The tendency of oxygen to be negatively ionized results in bombardment of the substrate sufficient to selectively resputter the film components (Kadin et al 1988; Rossnagal and Cuomo 1988). The problem is particularly severe in the case of composite targets of oxide superconductors as the rates of sputter deposition of these materials are much lower than those of pure metals in Ar. Since, for a given set of sputtering parameters, the growth rate and thickness profile depend upon the size of the target, it implies that because of backsputtering the composition profile of the deposited film would greatly depend upon the size of the composite target used.

\section{Experimental}

Although magnetron cathodes are expected to cause less back-sputtering due to lower cathode potentials, reported results indicate that the problem cannot be fully eliminated by the use of magnetron cathodes (Kadin et al 1988). Therefore, we studied 
the problem of backsputtering using a planar diode with an axial or longitudinal magnetic field. A schematic of the rf diode is shown in figure 1 . The primary purpose of the longitudinal magnetic field (300 gauss), which was applied using an external solenoid was to confine the plasma between the electrodes. The sputtering chamber was pumped with a cryo-cooled diffstak to a base pressure of $1 \times 10^{-6}$ torr. The rf power was coupled through a matching network using a $13.56 \mathrm{MHz}$ rf generator. The gases argon and oxygen were introduced into the chamber through two rotameters with fine control needle valves.

The sputtering targets were prepared by mixing required quantities of constituents $\mathrm{Y}_{2} \mathrm{O}_{3}, \mathrm{BaCO}_{3}$ and $\mathrm{CuO}$ followed by calcining at $900^{\circ} \mathrm{C}$ in air for 20 hours. The calcined mixture was then finely ground, pressed into discs of $35 \mathrm{~mm}$ and $65 \mathrm{~mm}$ diameters and sintered at $900^{\circ} \mathrm{C}$ for $10 \mathrm{~h}$. The composition of the targets before presputtering measured using energy dispersive $\mathrm{X}$-ray (EDX) analysis technique was

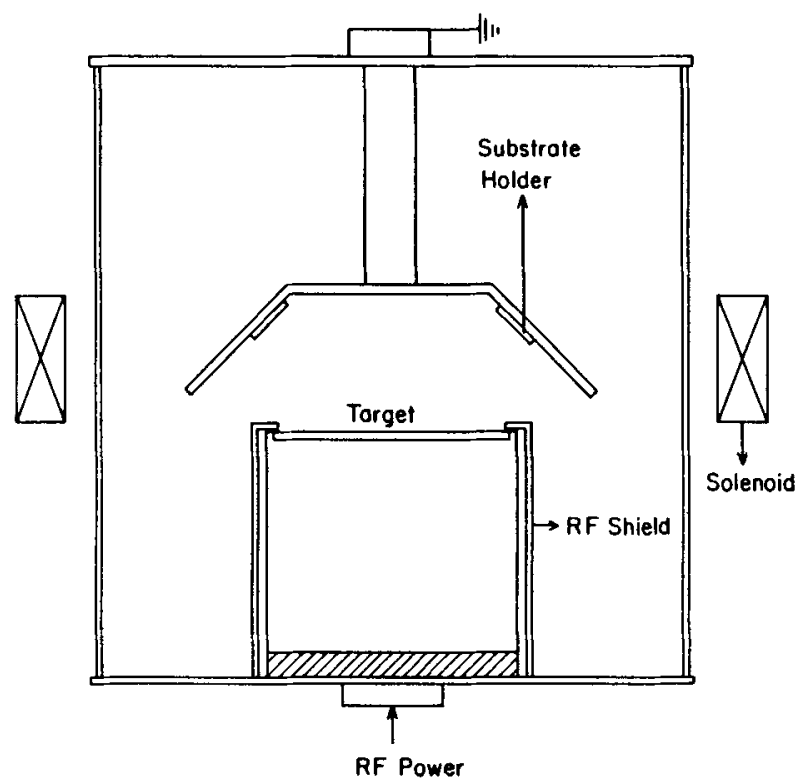

Figure 1. Schematic of $\mathrm{rf}$ diode with outer sections of the substrate holder inclined at $45^{\circ}$ to the axis.

Table 1. Sputtering conditions

\begin{tabular}{ll}
\hline Targets & $\mathrm{Y}_{11.5} \mathrm{Ba}_{37.5} \mathrm{Cu}_{51} \mathrm{O}_{x}$ (as prepared) \\
Diameter of targets & 35 and $65 \mathrm{~mm}$ \\
Magnetic field & $300 \mathrm{G}$ \\
Target-substrate spacing & $30 \mathrm{~mm}$ \\
Substrate temperature & $270^{\circ} \mathrm{C}$ and $450^{\circ} \mathrm{C}$ \\
Sputtering gas & $\mathrm{Ar}(80 \%)+\mathrm{O}_{2}(20 \%)$ \\
Gas pressure & $10^{-2}$ torr \\
If input power & $80 \mathrm{~W}$ \\
Growth rate & $55 \AA / \mathrm{min}$ \\
\hline
\end{tabular}


$\mathrm{Y}_{11.5} \mathrm{Ba}_{37.5} \mathrm{Cu}_{51} \mathrm{O}_{x}$. After presputtering for $10 \mathrm{~h}$, the surface composition was stabilized at $\mathrm{Y}_{14} \mathrm{Ba}_{39} \mathrm{Cu}_{47} \mathrm{O}_{x}$. The excess $\mathrm{Ba}$ and $\mathrm{Cu}$ in the targets over the '1-2-3' stoichiometric composition was intentional to make up for the loss due to backsputtering. All the work reported here was carried out using presputtered targets. The substrates used were $\langle 100\rangle \mathrm{Si},\langle 100\rangle \mathrm{SrTiO}_{3}$ and $\langle 100\rangle \mathrm{MgO}$. Silicon substrates were used only for characterizing the film composition and thickness. Films were deposited at $270^{\circ} \mathrm{C}$ (self-heated) and $450^{\circ} \mathrm{C}$ (heated with a platinum heater). Film thickness and composition were characterized using surface profilometer and EDX technique, respectively. The sputtering conditions are summarized in table 1 .

\section{Results and discussion}

The distributions of sputtered film composition and thickness were obtained both for $35 \mathrm{~mm}$ and $65 \mathrm{~mm}$ diameter targets with circular exposed areas of $30 \mathrm{~mm}$ and $60 \mathrm{~mm}$ diameters, respectively. Shown in figure 2 is the variation of composition of sputtered film with respect to the sputtering axis for $65 \mathrm{~mm}$ target. Shown also is the normalized thickness variation. The composition and thickness profiles were obtained after sputtering for $150 \mathrm{~min}$. It is seen that while the $\mathrm{Y}$ content in the film has a maximum at the centre, $\mathrm{Ba}$ and $\mathrm{Cu}$ contents are drastically reduced. Similarly, the thickness profile shows a minimum at the centre as opposed to the maximum one would obtain while sputtering metals in argon. As the compositions are drastically different from those of the target and since differences in sticking coefficients cannot account for such large variations, it implies that selertive backsputtering of the deposited film has occurred. Since the substrate holder was grounded with no rf bias, the backsputtering of the film has to be due to negatively charged oxygen ion bombardment. The extent to which backsputtering affects film composition and growth rate is shown in table 2 which



Figure 2. Variation of composition and normalized thickness of sputtered $\mathrm{Y}-\mathrm{Ba}-\mathrm{Cu}-\mathrm{O}$ film with distance from the sputtering axis for $65 \mathrm{~mm}$ target. Sputtering time is $150 \mathrm{~min}$. 
compares the composition and contribution of individual elements to the growth rate of the film obtained to the corresponding ideal values in the absence of backsputtering. The two assumptions made in this comparison are (i) $\mathrm{Y}$ is not backsputtered in the actual film and (ii) composition of the ideal film is the same as that of the original target. It is clear from table 2 that backsputtering of $\mathrm{Ba}$ and $\mathrm{Cu}$ is severe.

While the backsputtering effect due to negatively-charged oxygen ion bombardment is severe with $65 \mathrm{~mm}$ target, the results obtained with $35 \mathrm{~mm}$ target were much worse. The backsputtering in this case was so intense that there was no film at the central region of about $15 \mathrm{~mm}$ diameter. In fact, even the Ni-plated substrate holder was etched as confirmed by the presence of $\sim 2 \% \mathrm{Ni}$ in the deposited film. Hence, the $35 \mathrm{~mm}$ target was not used for any further work.

Figure 2 also shows that beyond $30 \mathrm{~mm}$ from the axis the composition approaches to near stoichiometry. This is obviously due to the reduced bombardment of oxygen ions. Although this region is of practical interest for the growth of stoichiometric $\mathrm{Y}-\mathrm{Ba}-\mathrm{Cu}-\mathrm{O}$ films, the much reduced growth rate in this region introduces practical problem in

Table 2. Comparison between actual and ideal values of film composition and growth rate at the centre.

\begin{tabular}{lccccc}
\hline & \multicolumn{2}{c}{ Actual } & & \multicolumn{2}{c}{ Ideal } \\
\cline { 2 - 3 } \cline { 5 - 6 } Element & $\begin{array}{c}\text { Composition } \\
(\%)\end{array}$ & $\begin{array}{c}\text { Growth rate } \\
(\AA / \mathrm{min})\end{array}$ & $\begin{array}{c}\text { Composition } \\
(\%)\end{array}$ & $\begin{array}{c}\text { Growth rate } \\
(\AA / \mathrm{min})\end{array}$ \\
\hline $\mathrm{Y}$ & 42.5 & 22.7 & 11.5 & 22.7 \\
$\mathrm{Ba}$ & 32.0 & 17.0 & & 37.5 & 74.0 \\
$\mathrm{Cu}$ & 25.5 & 13.6 & & 51.0 & 100.5 \\
Total & 100.0 & 53.3 & 100.0 & 197.2 \\
\hline
\end{tabular}

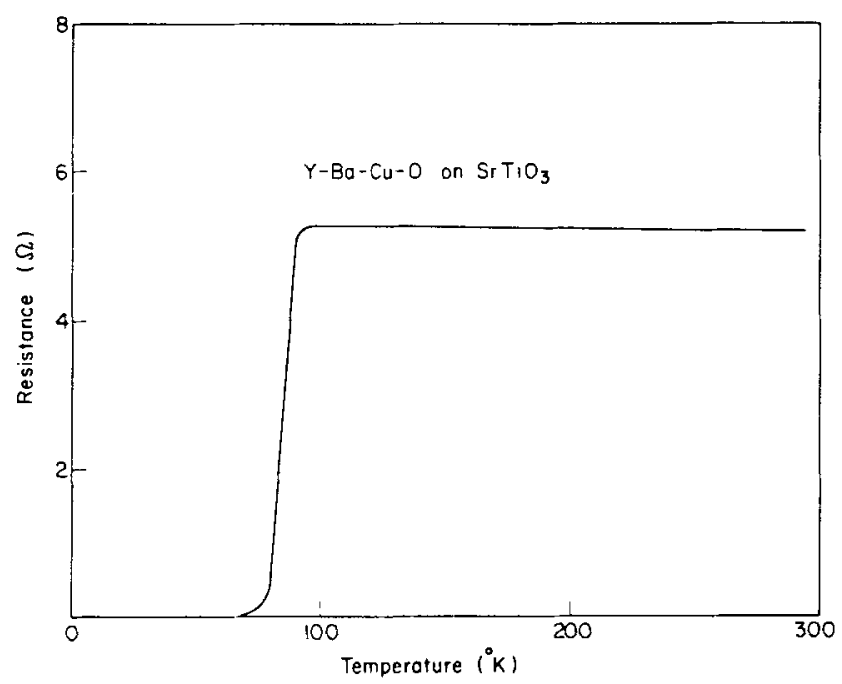

Figure 3. Temperature dependence of resistance of annealed $\mathrm{Y}-\mathrm{Ba}-\mathrm{Cu}-\mathrm{O}$ film sputtered on the inclined section of the substrate holder. 
obtaining reasonably thick films. We solved this problem by orienting the substrates at $45^{\circ}$ to the axis at a distance of $25 \mathrm{~mm}$ from the axis as shown in figure 1 . With this substrate orientation, it was possible to obtain a growth rate of $55 \AA / \mathrm{min}$ and a nearstoichiometric composition with a deviation $\leqslant 1 \%$ along $10 \mathrm{~mm}$ length of the inclined substrate. The composition obtained both at $270^{\circ} \mathrm{C}$ and $450^{\circ} \mathrm{C}$ has been found to be in the region $\mathrm{Y}_{16.5} \mathrm{Ba}_{33.5} \mathrm{Cu}_{50} \mathrm{O}_{x}-\mathrm{Y}_{17} \mathrm{Ba}_{34} \mathrm{Cu}_{49} \mathrm{O}_{x}$.

Films grown on both $\mathrm{SrTiO}_{3}$ and $\mathrm{MgO}$ substrates were annealed at $900^{\circ} \mathrm{C}$ for $30 \mathrm{~min}$ in oxygen followed by slow cooling. The contacts were made by evaporating $1.5 \mathrm{~mm}$ wide gold stripes with a $1 \mathrm{~mm}$ spacing. The room temperature resistivities were in the range $0.6-1 \mathrm{~m} \Omega \mathrm{cm}$. The low temperature resistivity was measured using pressure contacts made of gold-plated phosphor bronze probes. Shown in figure 3 is the $R$ vs $T$ curve for a typical film on $\langle 100\rangle \mathrm{SrTiO}_{3}$. $\mathrm{MgO}$ has also shown similar result. The relatively lower $T_{c}(R=0)$ of $72^{\circ} \mathrm{K}$ is presumed to be due to the small deviation from stoichiometry.

\section{Conclusions}

We have studied the problem of backsputtering caused due to negative oxygen ions in a rf diode with an axial magnetic field. Results indicate that the composition is drastically affected due to backsputtering when small composite $\mathrm{Y}-\mathrm{Ba}-\mathrm{Cu}-\mathrm{O}$ targets up to $65 \mathrm{~mm}$ diameter are used. It has been shown that by properly orienting the substrates with respect to the sputtering axis and choosing the appropriate target composition, stoichiometric $\mathrm{Y}-\mathrm{Ba}-\mathrm{Cu}-\mathrm{O}$ films could be obtained.

\section{Acknowledgements}

The authors would like to thank Professor R Vijayaraghavan for support. Thanks are also due to A K Rajarajan for preparing the targets, V T Karulkar and C P D'Souza for some of the experimental work, and S C Purandare for EDX analysis of samples.

\section{References}

Adachi H, Setsune K and Wasa K 1987 Phys. Rev. Lett. 358824

Adachi H, Hirochi K, Setsune K, Kitabatake M and Wasa K 1987 Appl. Phys. Lett. 512263

Aida T, Fukazawa T, Takagi K and Miyauchi K 1987 Jpn. J. Appl. Phys. 26 L1489

Broussard P R and Wolf S A 1988 J. Cryst. Growth 91340

Chaudhari P, Koch R H, Laibowitz R B, McGuire T R and Gambino R J 1987 Phys. Rev. Lett. 582684 Hong M, Kwo J and Yeh J J 1988 J. Cryst. Growth 91382

Kadin A M, Ballentine P H, Argana J and Rath R C 1988 in Superconductivity and its applications (eds) H S Kwok and D T Shaw (Amsterdam: Elsevier) p. 152

Kentgens A P M, Carim A H and Dam B 1988 J. Cryst. Growth 91355

Kwo J, Hsieh T C, Fleming R M, Hong M, Liou S H, Davidson B A and Feldman L C 1987 Phys. Rev. B36 4039

Rossnagal S M and Cuomo J J 1988 in Thin film processing and characterisation of high temperature superconductors, AIP Conference Proceedings N. 165 (eds) J M E Harper, R F Colton and L C Feldman (New York: American Institute of Physics) p. 106

Wu X, Dijkkamp D, Ogale S B, Inam A, Chase E W, Miceli P F, Chang C C, Tarascon J M and Venkatesan T 1987 Appl. Phys. Lett. 51861 